\title{
The advanced added skills developed by nurse managers / leaders in an island region: training needs
}

\section{Marlene Morais Ribeiro}

Enfermeira Especialista em Saúde Materna e Obstétrica, Mestre em Direção e Chefia de Serviços de Enfermagem. Serviço de Urgência, Unidade de Saúde Ilha do Pico - Açores.

Email: marlenemorais04@gmail.com

\begin{abstract}
Framework: The health service organizations expect manager nurses develop activities that foster the best quality scores both in terms of assistance and in terms of management. To do so, the managers have to master management skills.

Purpose: To understand the activity carried out by the manager nurses in an archipelago with several islands.

Methodology: Descriptive, analytical and exploratory study of quantitative nature. The data collection instrument was an autofill questionnaire which included a Perception Scale of the Work of the Nursing Manager.

The academic qualifications of the nursing managers are as follows: postgraduate studies in specific areas other than management $(15,9 \%)$; postgraduate studies in the field of management (36,5\%) and master's degree in different areas $(17,5 \%)$. The results in the field of the skills of management of nursing care may be the ones that require a bigger investment
\end{abstract}


in terms of training. Regarding the skills in the field of political intervention and advice, the results observed were below expectations.

Conclusion: The need for specific training in the field of management is quite obvious; we were able to prove that most of the manager nurses do not possess specific training in the field of management which would allow them to perform the management tasks based on solid knowledge.

Keywords: Skills of the managing nurse; Nursing leadership; quality of caring services.

\section{Introdução}

Uma região insular distingue-se pelas suas singularidades e idiossincrasias, facto que determina que as organizações de saúde existentes pelo arquipélago de nove ilhas sejam também elas singulares, o que faz com que a investigação em enfermagem no âmbito da problemática da atividade e das necessidades formativas na área de gestão dos Enfermeiros Gestores e Líderes assuma uma relevância indiscutível.

As múltiplas exigências, os ambientes em mudança e os avanços científicos e tecnológicos requerem um aumento substancial das responsabilidades dos Enfermeiros Gestores implicando continuamente a redefinição das suas funções e papéis, e um olhar atento sobre a evolução das suas competências (Rocha et al., 2016).

Olhar, implica uma visão zoom sobre a gestão, pois esta é uma atividade complexa e exige, refletir sobre os modelos de intervenção em gestão o que implica falar de necessidades formativas versus competências. "As competências são hoje um vetor extremamente relevante e poderoso nos processos de gestão. Esta importância torna-se ainda mais visível, se falarmos concretamente na gestão de recursos humanos a gestão de pessoas" (Ceitil, 2016, p. 127).

Os modelos atuais de gestão, têm demonstrado a importância de uma gestão participativa de todos os intervenientes das organizações, realidade transversal na área da saúde, contudo para que esta participação seja válida é exigido aos Enfermeiros Gestores preparação e domínio de competências que demonstrem a sua utilidade no processo de gestão. 
Neste contexto foi conduzido o processo de investigação com os seguintes objetivos: Compreender a atividade dos Enfermeiros Gestores numa região insular e identificar áreas de formação conducentes às competências acrescidas avançadas dos gestores de enfermagem.

\section{Enquadramento:}

A importância dos Enfermeiros Gestores serem detentores de formação na área da gestão é uma premissa relevante e com influência direta no seu estilo de liderança, promovendo a autorreflexão e consequentemente diligenciando práticas mais adequadas aos seus contextos de trabalho.

Ceitil (2016, p.102) tem patente o significado de competência como "o conjunto de aprendizagens sociais e comunicacionais, alimentadas pela aprendizagem e formação e complementadas pelo sistema de avaliação que permite mais tarde atualizar a competência e introduzir as melhorias necessárias”.

Muito da gestão em enfermagem é levar a equipe a prestar os melhores cuidados com os recursos disponíveis pelo que "os gestores com capacidades humanas conseguem obter o melhor dos outros, pois sabem como comunicar, motivar, liderar, conseguindo transmitir um entusiasmo motivador e confiança aos outros" Costa (2018, p. 26).

Envolver os seguidores além das expetativas, estabelecer autoridade de liderança e integridade, ao mesmo tempo que se inspira e motiva os subordinados é competência dos Enfermeiros Gestores. Neste contexto, as principais competências de liderança passam pela influência idealizada, a motivação inspirada, estimulação intelectual e consideração individual, Chipeta et al. (2016) elencam que as principais determinantes da motivação e do desempenho organizacional são as práticas de liderança e reconhecem que estas práticas têm uma dimensão cada vez mais significativa nos resultados de qualidade nos cuidados de saúde.

Moura et al. (2017) preconiza que o líder em enfermagem, atua como aquele que permite a comunicação franca e aberta, que tem a capacidade de reconhecer e atender às necessidades da equipa, sabe apoiar nos momentos necessários, fomenta a harmonia no ambiente de trabalho; é alguém que trabalha em prol da união e integração da equipa, assegurando a satisfação dos enfermeiros e consequentemente a qualidade dos cuidados prestados aos clientes. 
Costa (2018) acrescenta que os gestores ampliam valor aos recursos influenciando as pessoas com que eles interagem. A função de planear, organizar, dirigir e controlar depende da adesão de todos os envolvidos para colaborar numa rede de mútua influência. Patenteia que um líder é aquele que pode influenciar os outros e detém competências para o fazer.

Camelo et al. (2017) partem da premissa que o enfermeiro gestor necessita liderar a sua equipa de trabalho com o intuito de alcançar o sucesso o que torna imprescindível o uso da liderança como competência. Nesta perspetiva, concordamos que o aprimoramento destas habilidades por meio do modelo de outros gestores e da formação direcionada são estratégias para ganhos de competências de liderança que são exigidas ao Enfermeiro Gestor.

Munyewende e colaboradores (2016) definem competência como habilidades técnicas, conhecimento e atitudes necessárias para executar um trabalho. Descortinam as competências na gestão estratégica, financeira e de recursos humanos; inovação na prestação de serviços; orientação e foco ao cliente; e a comunicação como sendo essenciais para atingir os objetivos organizacionais.

As competências específicas como o próprio nome indica, são aquelas que são requeridas para atividades ou contextos mais restritos, geralmente associadas a domínios técnicos e instrumentais. Outros investigadores relativamente às competências da gestão, identificam três tipos de competências essenciais para a atividade de gerir: competências técnicas, competências humanas e competências conceptuais (Ceitil, 2016; Costa, 2018).

As competências conceptuais são as habilidades que os gestores utilizam para pensar e conceptualizar sobre posições abstratas e complexas. Ceitil (2016) afirma que os gestores com este tipo de competências conseguem visualizar a organização como um todo, coordenar e integrar os interesses e atividades da organização. Estas competências são especialmente importantes na gestão de topo.

Todavia, existem outras competências que assumem importância ascendente e que são exigidas aos gestores, tais como: capacidade para gerir o capital humano, a mudança, o processo de tomada de decisão, a estratégia, a inovação, a logística, e a tecnologia, entre outras (Costa, 2018).

Concordamos que sistemas de saúde com grau de complexidade exigem aos Enfermeiros Gestores competências adicionais como as aqui enunciadas para que se promova uma gestão de planeamento, direção, coordenação e controle eficazes. Não podemos menosprezar que as 
competências de gestão são muito importantes para a melhoria da qualidade dos cuidados de enfermagem no cliente.

O papel do enfermeiro gestor não pode deixar de parte a centralidade do seu exercício de enfermeiro, recordemos que o Regulamento do Exercício Profissional de Enfermagem (REPE) define e destaca o papel fundamental do enfermeiro enquanto profissional dotado de competências científicas, técnicas e humanas para a prestação de cuidados à pessoa, durante o seu ciclo vital, enquanto ser holístico que integra e interage com a sua família, grupo ou comunidade, necessitando de cuidados que visem a promoção da saúde e a prevenção da doença nos seus diferentes níveis de prevenção (Dec. Lei n. ${ }^{\circ}$ 161/96, de 4 de Setembro, alterado pelo Dec. Lei no 104/98, de 21 de Abril).

É importante recordar que o enfermeiro gestor, tem uma exigência acrescida, expressa legalmente a partir de 2015, em Portugal, com a publicação do regulamento das competências do enfermeiro gestor, sendo que em janeiro de 2018, é regulamentada a Competência Acrescida Avançada em Gestão através do Regulamento No 76/2018 (DR, 2. ${ }^{\text {a }}$ Série - N. ${ }^{\circ}$ 21, 2018).

Presentemente, a atual legislação das alterações à carreira, constatam que as funções de enfermeiro gestor estão preceituadas, no Dec. Lei No 71/2019 de 27 de maio. O Art. 10B Relativamente ao conteúdo funcional do enfermeiro gestor consagra “...o conteúdo funcional integra, na generalidade, as funções de planeamento, organização, direção e avaliação dos cuidados de enfermagem, utilizando um modelo facilitador do desenvolvimento organizacional e promotor da qualidade e segurança..." (Dec. Lei nº71/2019, p.2628). O enfermeiro gestor terá que percecionar os novos conceitos de gestão, e saber "ser" e "estar" perante os desafios, porém durante os procedimentos de gestão ocorrem oportunidades onde os enfermeiros gestores podem ser os atores na organização e realizar uma mudança estratégica com sucesso.

Questão de investigação: "Será que os Enfermeiros Gestores na região insular desenvolvem as competências acrescidas avançadas na sua área de atuação?”

\section{Metodologia:}

Perante a não existência de dados sobre o problema em estudo delineamos um estudo descritivo, exploratório com abordagem quantitativa. A população é constituída por todos os 
Enfermeiros Gestores (chefias de topo, categorias subsistentes e a exercerem as funções de chefia) nas unidades que constituem a amostra e estarem ao serviço durante o período de colheita de dados, num total de 63 participantes dos 102 enfermeiros que constituem a população, representando $(61.76 \%)$ desta, sendo estes oriundos de: 3 hospitais, 8 Unidades de saúde, 2 Casas de Saúde e 4 Lares de Idosos.

O instrumento de colheita de dados é composto por duas partes. A primeira alude aos dados sociodemográficos e profissionais (género, idade, anos de exercício profissional, anos de exercício na área de gestão, anos no atual serviço, área de especialidade, graus académicos, natureza da instituição e natureza da exploração). A segunda parte integra a Escala de Perceção do Trabalho do Gestor em Enfermagem (EPTGE - Martins, MM; Gonçalves, MN, 2012), organizado com 5 questões desdobradas com atividades desenvolvidas na área da gestão, tendo como referência as competências acrescidas avançadas do enfermeiro gestor da OE, sendo composto por 43 itens cujas respostas são dadas numa escala de Likert que permite avaliar as dimensões das atividades do enfermeiro gestor: Prática Profissional, ética e legal (5 atividades variação de 5 a 20 pontos), Gestão de Cuidados (14 atividades com variação de 14 a 56 pontos), Gestão de Recursos Humanos (14 atividades com variação de 14 a 56 pontos), Intervenção Política e Assessoria (6 atividades com variação de 6 a 24 pontos), Desenvolvimento Profissional (4 atividades com variação de 4 a 16 pontos) e cada atividade foi classificada como sendo realizada: nunca ( 1 ponto), poucas vezes ( 2 pontos), algumas vezes ( 3 pontos) e sempre ( 4 pontos). Optou-se por uma escala de quatro pontos para evitar a opção de tendência central nas respostas.

Os scores de cada uma das subescalas são calculados a partir do somatório de cada um dos itens pertencentes a cada uma delas. Globalmente a escala pode variar entre a 43 a 172 pontos, situando-se os 43 como a situação de não fazer atividades de gestão e o 172 o fazer atividades de gestão de acordo com a melhor representação destas atividades. A escala original apresenta um valor do Alfa para a totalidade do questionário é de 0,95 , o que é um valor muito elevado e mostra uma consistência interna da escala muito forte, foi efetuado um cálculo amostral, com um nível de confiança de $95 \%$ expõe uma margem de erro de 7,67\%, resultando numa amostra de 63 indivíduos.

Foi obtida autorização de utilização da escala EPTGE aos autores e foi obtida autorização de recolha de colheita de dados pelos Conselhos de Administração das 17 instituições de Saúde e pareceres favoráveis das comissões de ética dos mesmos. Foram efetuados contatos de esclarecimento aos enfermeiros gestores acerca dos objetivos, finalidades e pertinência do 
estudo. Considerando a dispersão territorial, a escala foi entregue em formato digital e disponível através de link. A plataforma disponível on line, elegida foi o Google forms ${ }^{\circledR} \mathrm{e}$ posterior importação para o programa de tratamento estatístico de dados - SPSS ${ }^{\circledR}$.

Foi solicitada participação após consentimento informado. Foi garantido o anonimato e a confidencialidade dos dados colhidos, respeitada a autonomia e, ainda, foi dada a liberdade de participação e a possibilidade de em qualquer altura querer desistir. A recolha de dados decorreu no período compreendido entre 1 outubro 2018 e 28 de fevereiro 2019.

Resultados: A maioria dos Enfermeiros Gestores é do género feminino (61.9\%). Registou-se a idade mínima de 25 anos e a máxima de 65 anos, sendo a idade média 47.37 anos. Os anos de exercício profissional apresentam um mínimo de 4 anos e um máximo de 40 anos, sendo uma média de 23.47 anos de exercício profissional. O número de anos de exercício na área de gestão obteve-se uma variação entre 0 e 31 anos, sendo a média 9.38 anos. O número de anos no atual serviço verifica um valor entre 0 e 32 anos com uma média de 9.37 anos. A área de especialidade do enfermeiro gestor verificou-se que o titulo de enfermeiro especialista em Médico-Cirúrgica é o predominante com (28.6\%), seguido de titulo de enfermeiro especialista em Comunitária com (14.3\%). Por conseguinte, em relação ao Grau Académico (81\%) dos enfermeiros gestores têm licenciatura, (17.5\%) têm Mestrado e (1.6\%) é detentor de Doutoramento. A natureza da instituição mais representativa são os Hospitais com (54\%), seguidas das Unidades de Saúde Ilha com (25.4\%) e as outras Instituições são representadas em minoria (20.6\%). A natureza da exploração mais expressiva é do setor público (82.5\%) seguido os outros setores (17.4\%).

As competências desenvolvidas pelos Enfermeiros Gestores da observação das médias observadas, verificamos que os Enfermeiros Gestores desenvolvem atividades que tornam a sua intervenção Pratica Profissional Ética e Legal muito positiva. Quando se analisa esta componente, numa perspetiva quantitativa verificamos uma variação de 14 a 20, sendo a moda em 20 e a média em 19,50 com um desvio padrão de 1,667 contudo a sua distribuição não segue a curva normal. Verifica-se os valores das frequências com maior incidência para o polo positivo da subescala o que podemos afirmar que os gestores do estudo se encontram todos acima do ponto média da subescala e com uma média superior ao ponto médio (Tabela $1)$.

Tabela1. Pratica Profissional Ética e Legal

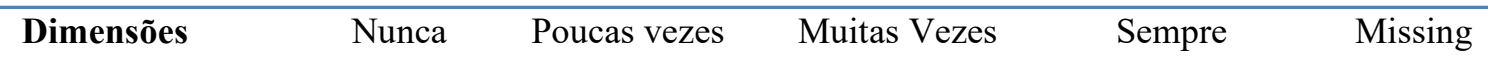




\begin{tabular}{lllllllllll}
\hline $\mathbf{N}^{0}$ & $\%$ & $\mathbf{N}^{0}$ & $\%$ & $\mathbf{N}^{0}$ & $\%$ & $\mathbf{N}^{0}$ & $\%$ & $\mathbf{N}^{0}$ & $\%$
\end{tabular}

Preocupa-se com os

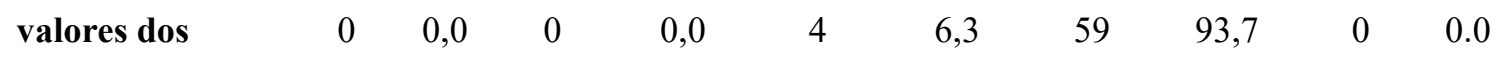

enfermeiros

Preocupa-se com os

valores dos doentes

$\begin{array}{llllllllll}0 & 0,0 & 0 & 0,0 & 4 & 6,3 & 59 & 93,7 & 0 & 0.0\end{array}$

Discute questões éticas

relacionadas com os

cuidados com a sua

$0 \quad 0,0$

$14,3-27$

$42,9 \quad 27$

42,9 0

0.0

equipe

Controla o respeito

pela privacidade e

individualidade do

20

31,7

42

$66,7 \quad 1$

1,6

doente

Garante condições

legais para os

cuidados e exercício

$0 \quad 0,0 \quad 4$

$13 \quad 20,6$

46

73,0

0

0.0

profissional

Relativamente as atividades desenvolvidas na componente da Gestão de Cuidados (tabela 2), verificamos uma variação de 21 a 56, com uma moda de 54 e uma média de 46,40 com um desvio padrão de 7,461, esta componente também faz a sua distribuição no sentido positivo da escala. Podemos verificar (Tabela 2), mais uma vez, que os enfermeiros gestores do estudo apresentam uma média superior ao ponto médio da subescala. Face aos resultados podemos afirmar que os gestores desenvolvem atividades de tal forma que, no global para a Gestão de Cuidados a sua intervenção é positiva.

Tabela 2. Gestão de Cuidados

\begin{tabular}{|c|c|c|c|c|c|c|c|c|c|c|}
\hline \multirow[t]{2}{*}{ Dimensões } & \multicolumn{2}{|c|}{ Nunca } & \multicolumn{2}{|c|}{ Poucas vezes } & \multicolumn{2}{|c|}{ Muitas Vezes } & \multicolumn{2}{|c|}{ Sempre } & \multicolumn{2}{|c|}{ Missing } \\
\hline & $\mathbf{N}^{\mathbf{0}}$ & $\%$ & $\mathbf{N}^{\mathbf{0}}$ & $\mathbf{N}^{\mathbf{0}}$ & $\%$ & $\%$ & $\mathbf{N}^{\mathbf{0}}$ & $\%$ & $\mathbf{N}^{\mathbf{o}}$ & $\%$ \\
\hline Discute com os & & & & & & & & & & \\
\hline $\begin{array}{l}\text { enfermeiros decisões } \\
\text { sobre cuidados }\end{array}$ & 1 & 1,6 & 3 & 4,8 & 25 & 39,7 & 34 & 54,0 & 0 & 0.0 \\
\hline Promove a tomada de & 2 & 3,2 & 4 & 6,3 & 25 & 39,7 & 32 & 50,8 & 0 & 0.0 \\
\hline
\end{tabular}




\begin{tabular}{|c|c|c|c|c|c|c|c|c|c|c|}
\hline decisão clínica & & & & & & & & & & \\
\hline $\begin{array}{c}\text { Acompanha a } \\
\text { execução de cuidados } \\
\text { de forma planeada }\end{array}$ & 2 & 3,2 & 10 & 15,9 & 31 & 49,2 & 20 & 31,7 & 0 & 0.0 \\
\hline $\begin{array}{c}\text { Prevê e assegura os } \\
\text { meios e recursos } \\
\text { necessários à } \\
\text { prestação de cuidados }\end{array}$ & 1 & 1,6 & 20 & 31,7 & 41 & 65,1 & 0 & 0.0 & 1 & 1,6 \\
\hline $\begin{array}{l}\text { Discute riscos dos } \\
\text { doentes face aos } \\
\text { cuidados e condições } \\
\text { do serviço }\end{array}$ & 0 & 0,0 & 4 & 6,3 & 26 & 41,3 & 33 & 52,4 & 0 & 0.0 \\
\hline $\begin{array}{l}\text { Toma decisões de } \\
\text { forma a garantir os } \\
\text { melhores cuidados } \\
\text { para os doentes }\end{array}$ & 2 & 3,2 & 12 & 19,0 & 48 & 76,2 & 0 & 0.0 & 1 & 1,6 \\
\hline $\begin{array}{c}\text { Garante dotações } \\
\text { seguras de acordo com } \\
\text { os padrões de } \\
\text { qualidade da profissão }\end{array}$ & 5 & 7,9 & 11 & 17,5 & 26 & 41,3 & 21 & 33,3 & 0 & 0.0 \\
\hline $\begin{array}{l}\text { Analisa e avalia a } \\
\text { qualidade dos } \\
\text { cuidados e } \\
\text { implementa medidas } \\
\text { corretivas }\end{array}$ & 2 & 3,2 & 6 & 9,5 & 30 & 47,6 & 25 & 39,7 & 0 & 0.0 \\
\hline $\begin{array}{l}\text { Orienta cuidados de } \\
\text { maior complexidade }\end{array}$ & 4 & 6,3 & 6 & 9,5 & 25 & 39,7 & 28 & 44,4 & 0 & 0.0 \\
\hline $\begin{array}{c}\text { Desenvolve planos de } \\
\text { melhoria contínua da } \\
\text { qualidade }\end{array}$ & 3 & 4,8 & 8 & 12,7 & 35 & 55,6 & 17 & 27 & 0 & 0.0 \\
\hline $\begin{array}{c}\text { Elabora, aplica, avalia } \\
\text { e atualiza } \\
\text { procedimentos } \\
\text { orientadores da } \\
\text { utilização de }\end{array}$ & 2 & 3,2 & 12 & 19,0 & 27 & 42,9 & 22 & 34,9 & 0 & 0.0 \\
\hline
\end{tabular}




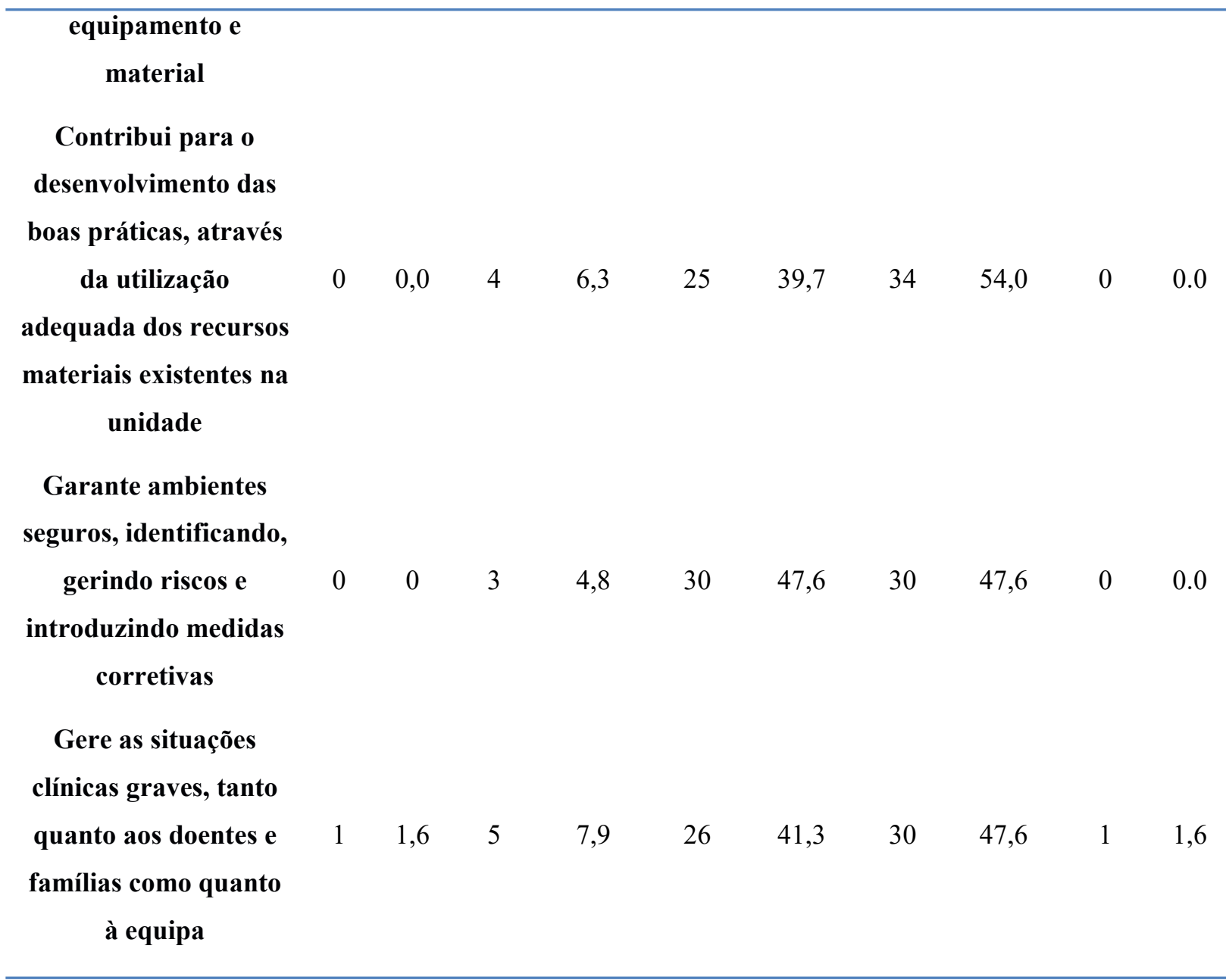

Na tabela 3 está representada a componente Gestão de Recursos Humanos que apresenta uma variação de 20 a 56, com uma moda de 55 e uma média de 45,38 com um desvio padrão de 8,481 , esta componente também faz a sua distribuição no sentido positivo da escala.

Tabela 3. Gestão de Recursos Humanos

\begin{tabular}{|c|c|c|c|c|c|c|c|c|c|c|}
\hline \multirow[t]{2}{*}{ Dimensões } & \multicolumn{2}{|c|}{ Nunca } & \multicolumn{2}{|c|}{ Poucas vezes } & \multicolumn{2}{|c|}{ Muitas Vezes } & \multicolumn{2}{|c|}{ Sempre } & \multicolumn{2}{|c|}{ Missing } \\
\hline & $\mathbf{N}^{\mathbf{o}}$ & $\%$ & $\mathbf{N}^{\mathbf{0}}$ & $\%$ & $\mathbf{N}^{\mathbf{0}}$ & $\%$ & $\mathbf{N}^{\mathbf{0}}$ & $\%$ & $\mathbf{N}^{\mathbf{0}}$ & $\%$ \\
\hline $\begin{array}{l}\text { Promove reuniões } \\
\text { com os enfermeiros }\end{array}$ & 1 & 1,6 & 8 & 12,7 & 17 & 27,0 & 37 & 58,7 & 0 & 0.0 \\
\hline $\begin{array}{c}\text { Assiste à passagem de } \\
\text { turno }\end{array}$ & 12 & 19,0 & 9 & 14,3 & 10 & 15,9 & 30 & 47,6 & 2 & 3,2 \\
\hline $\begin{array}{l}\text { Avalia o desempenho } \\
\text { dos enfermeiros }\end{array}$ & 5 & 7,9 & 5 & 7,9 & 11 & 17,5 & 42 & 66,7 & 0 & 0.0 \\
\hline $\begin{array}{c}\text { Coordena o processo } \\
\text { de integração dos }\end{array}$ & 4 & 6,3 & 4 & 6,3 & 12 & 19,0 & 43 & 68,3 & 0 & 0.0 \\
\hline
\end{tabular}




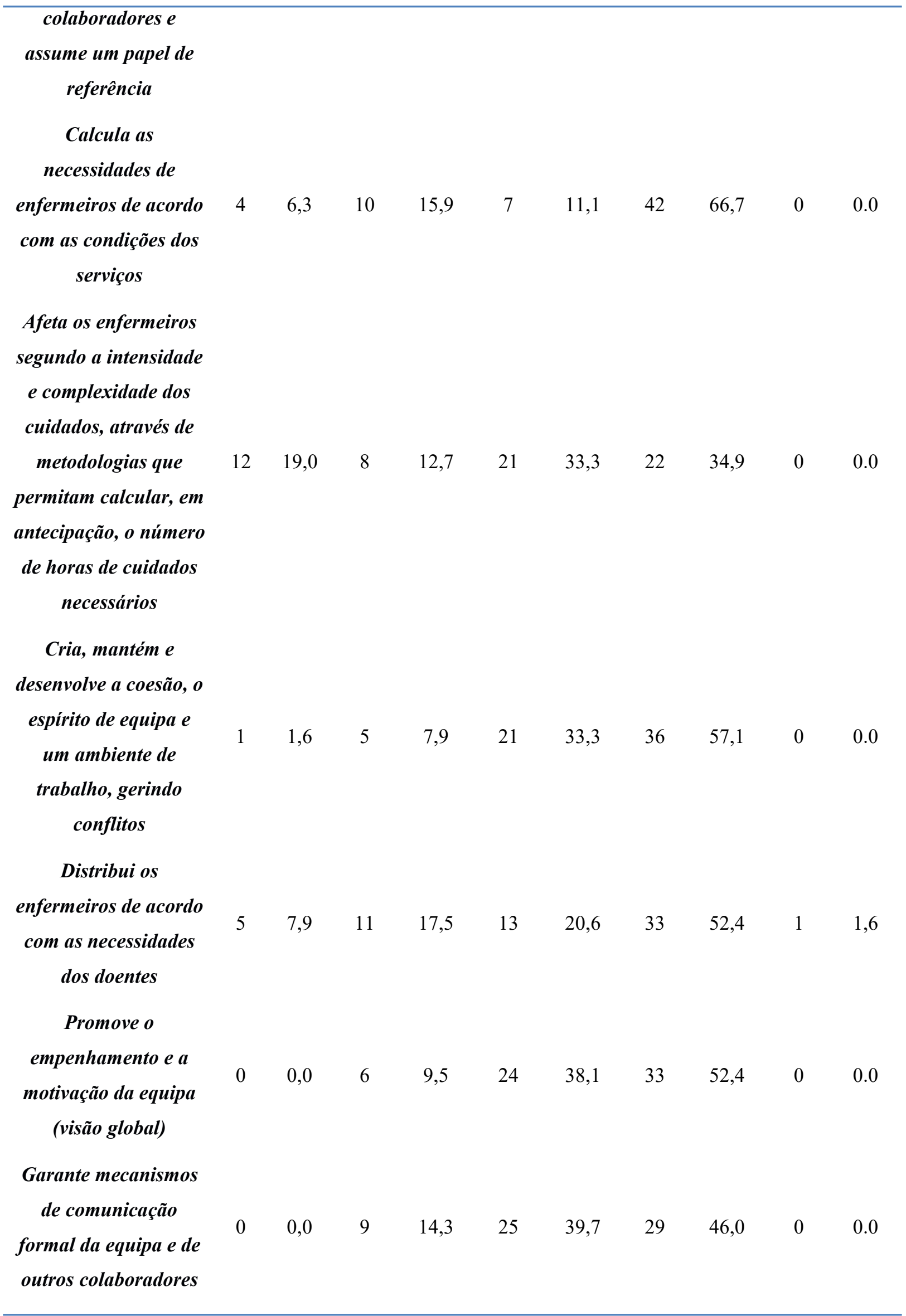




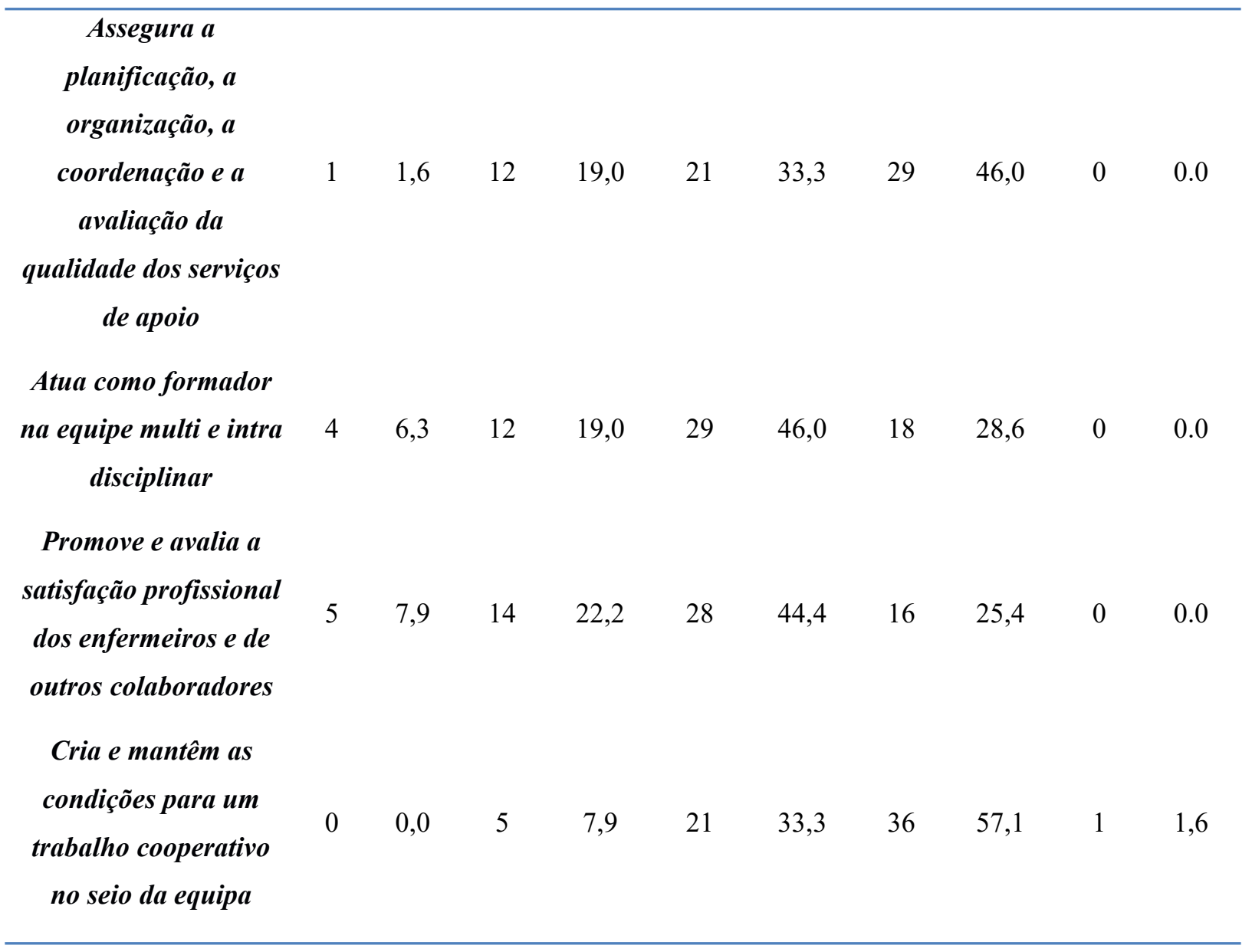

Como se pode verificar na Gestão de Recursos Humanos, embora continue a ser positiva a pontuação atribuída pelos enfermeiros gestores, demonstra que existem atividades que necessitam de serem repensadas, entre as quais: assistir às passagens de turno; afetar os enfermeiros segundo a intensidade e complexidade dos cuidados; atuar como formador e promover a avaliação da satisfação profissional do enfermeiro e de outros profissionais.

A componente Intervenção Política e Assessoria (Tabela 4) apresenta uma variação de 10 a 24 , com uma moda de 18 e uma média de 17,97 com um desvio padrão de 3,545; esta componente também faz a sua distribuição no sentido positivo da escala, ocorrendo apenas uma resposta omissa.

Tabela 4. Intervenção Política e Assessoria

\begin{tabular}{|c|c|c|c|c|c|c|c|c|c|c|}
\hline \multirow[t]{2}{*}{ 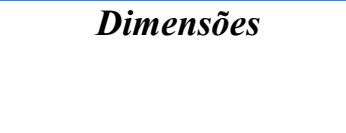 } & \multicolumn{2}{|c|}{ Nunca } & \multicolumn{2}{|c|}{ Poucas vezes } & \multicolumn{2}{|c|}{ Muitas Vezes } & \multicolumn{2}{|c|}{ Sempre } & \multicolumn{2}{|c|}{ Missing } \\
\hline & $\mathrm{N}^{0}$ & $\%$ & $\mathrm{~N}^{0}$ & $\%$ & $\mathbf{N}^{0}$ & $\%$ & $\mathbf{N}^{0}$ & $\%$ & $\mathrm{~N}^{0}$ & $\%$ \\
\hline $\begin{array}{c}\text { Participa na definição } \\
\text { e implementação de } \\
\text { políticas de saúde do }\end{array}$ & 5 & 7,9 & 13 & 20,6 & 32 & 50,8 & 12 & 19,0 & 1 & 1,6 \\
\hline
\end{tabular}




\begin{tabular}{|c|c|c|c|c|c|c|c|c|c|c|}
\hline hospital & & & & & & & & & & \\
\hline $\begin{array}{c}\text { Participa no } \\
\text { planeamento } \\
\text { estratégico do serviço }\end{array}$ & 4 & 6,3 & 5 & 7,9 & 28 & 44,4 & 25 & 39,7 & 1 & 1,6 \\
\hline $\begin{array}{c}\text { Elabora relatórios de } \\
\text { serviço }\end{array}$ & 7 & 11,1 & 10 & 15,9 & 28 & 44,4 & 17 & 27,0 & 1 & 1,6 \\
\hline $\begin{array}{c}\text { Concebe e } \\
\text { operacionaliza projetos } \\
\text { no serviço, implica-se e } \\
\text { implica a equipa no } \\
\text { desenvolvimento e na } \\
\text { implementação de } \\
\text { projetos } \\
\text { organizacionais }\end{array}$ & 5 & 7,9 & 8 & 12,7 & 27 & 42,9 & 22 & 34,9 & 1 & 1,6 \\
\hline $\begin{array}{c}\text { Adapta os recursos } \\
\text { materiais às }\end{array}$ & & & & & & & & & & \\
\hline $\begin{array}{c}\text { necessidades, tendo em } \\
\text { conta a relação custo- } \\
\text { benefício }\end{array}$ & 0 & 0,0 & 9 & 14,3 & 18 & 28,6 & 35 & 55,6 & 1 & 1,6 \\
\hline $\begin{array}{c}\text { Participa em grupos de } \\
\text { trabalho e comissões }\end{array}$ & & & & & & & & & & \\
\hline $\begin{array}{c}\text { na área da gestão de } \\
\text { risco clínico e não } \\
\text { clínico }\end{array}$ & 13 & 20,6 & 15 & 23,8 & 19 & 30,2 & 15 & 23,8 & 1 & 1,6 \\
\hline
\end{tabular}

É de salientar a necessidade dos enfermeiros gestores na área da Intervenção Política e Assessoria desenvolverem mais participação na definição e implementação de política de saúde; maior participação em grupos de trabalho e comissões na área da gestão de risco clínico e não clínico.

Tabela 5. Desenvolvimento profissional

\begin{tabular}{|c|c|c|c|c|c|c|c|c|c|c|}
\hline \multirow[t]{2}{*}{ Dimensões } & \multicolumn{2}{|c|}{ Nunca } & \multicolumn{2}{|c|}{ Poucas vezes } & \multicolumn{2}{|c|}{ Muitas Vezes } & \multicolumn{2}{|c|}{ Sempre } & \multicolumn{2}{|c|}{ Missing } \\
\hline & $\mathbf{N}^{\mathbf{o}}$ & $\%$ & $\mathbf{N}^{0}$ & $\%$ & $\mathbf{N}^{0}$ & $\%$ & $\mathbf{N}^{\mathbf{0}}$ & $\%$ & $\mathbf{N}^{\mathbf{0}}$ & $\%$ \\
\hline $\begin{array}{c}\text { Promove a enfermagem } \\
\text { baseada na evidência }\end{array}$ & 4 & 6,3 & 4 & 6,3 & 25 & 39,7 & 30 & 47,6 & 0 & 0.0 \\
\hline
\end{tabular}




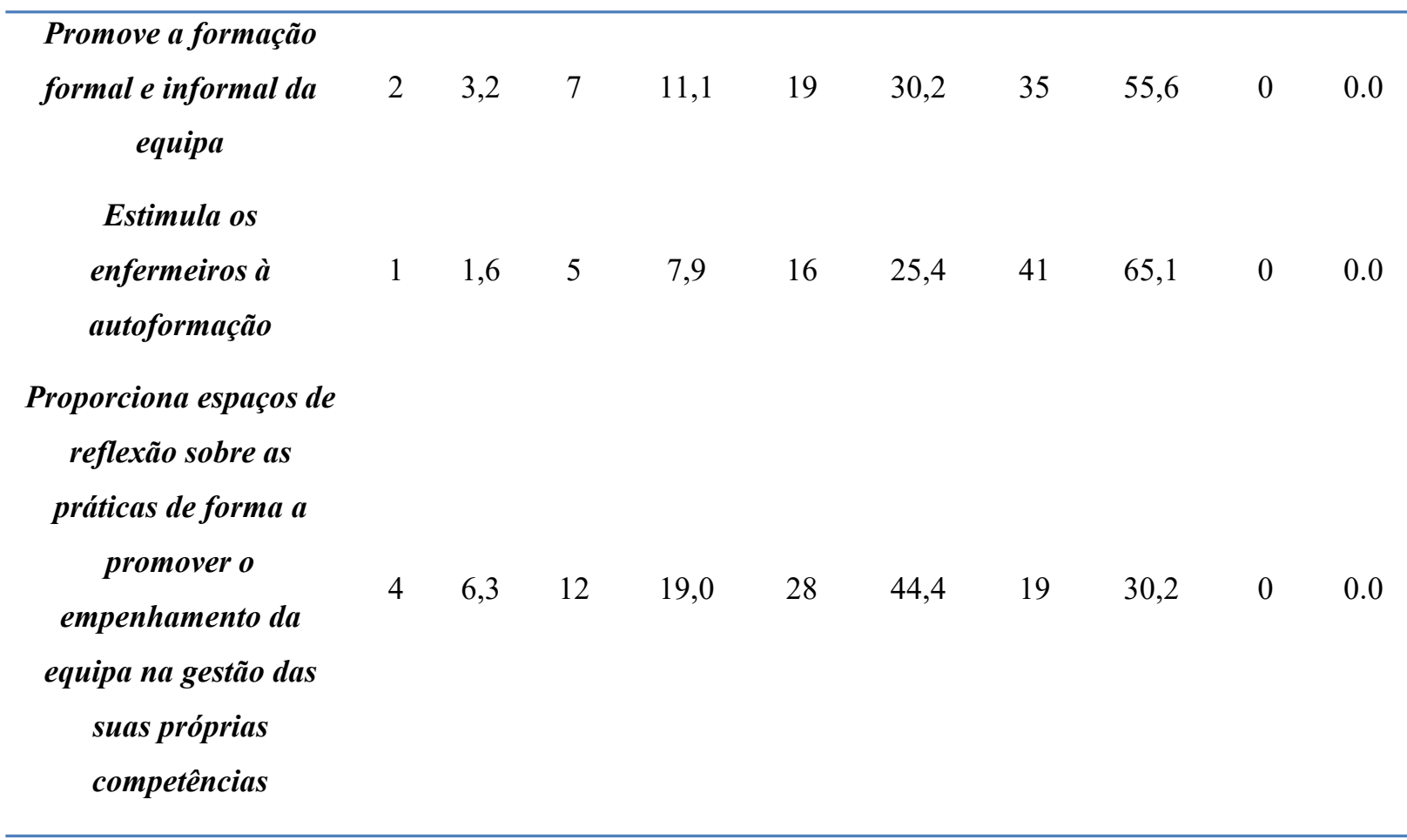

Quando analisada a componente Desenvolvimento Profissional, representada na tabela 5, verificamos uma variação de 6 a 16, com uma moda que ocorre no 15 e16, a média de 13,19 com um desvio padrão de 2,711, esta componente também faz a sua distribuição no sentido positivo da escala. Podemos afirmar que a dimensão que necessita de maior atenção é proporcionar espaços de reflexão sobre as práticas de forma a promover o empenhamento da equipa na gestão das suas próprias competências.

As atividades dos enfermeiros gestores que fazem parte desta amostra representam todas as áreas de competências do enfermeiro gestor, sendo de sublinhar que a maioria pratica as suas atividades em todos os domínios do "Sempre", notando-se algumas fragilidades na dimensão Intervenção Política e Assessoria, considerando que só "Às vezes" o fazem. Para a opção "Nunca" nenhuma atividade de gestão tem frequência superior a dez.

Discussão: A amostra é maioritariamente do género feminino (61.9\%). Perspetiva histórica da enfermagem e aferindo o Relatório 2018 e Contas da OE, este valida "A 31 de dezembro 2018, existiam 73912 membros da OE. Da totalidade dos membros, 60737 são do género feminino e 13175 do género masculino" (p.16).

Em relação aos grupos etários dos enfermeiros gestores e líderes, nesta amostra a faixa etária mais representativa é 51 e 60 anos com 39,7\%. A distribuição dos enfermeiros gestores por anos de exercício profissional variou entre 9 e os 40 anos de exercício da profissão, surgindo dois registos mais representativos com idade compreendidas no intervalo, entre 20 e os 29 anos e os 30 e os 40 anos de idade, ambas (33,3\%) de representatividade. No que diz respeito 
ao tempo de exercício profissional na área de gestão constatou-se que os enfermeiros têm entre 0 a 31 anos de experiência na área da gestão, verificando-se que a maior percentagem dos enfermeiros que exerce essa função de gestão entre os 0 e 9 anos $(63,5 \%)$.

As habilitações académicas, que os enfermeiros gestores $(15,9 \%)$ detêm são pós-graduações em áreas específicas sem ser em gestão. Contudo cerca de $(36,5 \%)$ dos enfermeiros participantes no estudo têm pós-graduação na área da gestão e curso de mestrado (17,5\%).

A análise da componente Prática Profissional Ética e Legal permitiu concluir com opinião dos participantes que se preocupam "sempre" com os valores dos enfermeiros e com os valores dos doentes ambos com (93,7\%), sendo o valor mais baixo verificado na dimensão discute questões éticas relacionadas com os cuidados com a sua equipa no total (42,9\%). Estes resultados são concordantes com outras pesquisas que valorizam a essencialidade para um Enfermeiro Gestor ter foco no cliente e no enfermeiro, promovendo ambiente profissional ético e legal. Lelli et al. (2012) expressam a importância da competência de liderança na prática profissional, na organização, na confiança e direcionamento da equipa de trabalho.

$\mathrm{Na}$ componente da Gestão de Cuidados constata-se que a dimensão discute com os enfermeiros decisões sobre os cuidados $(54,0 \%)$ respondem que "sempre" exercem a competência. Nesta premissa uma das formas de se garantir que essa competência seja desenvolvida e aprimorada no ambiente da prática do Enfermeiro Gestor é que a mesma deva ser incrementada através da vertente formativa. Neste contexto, o estudo de Fradique, M. e Mendes, L. (2013) elenca um modelo estrutural sugestivo, de que a liderança em enfermagem está diretamente relacionada com a qualidade dos cuidados de enfermagem prestados, sendo o "cliente" o foco do processo.

Estimando a componente da Gestão de Recursos Humanos à semelhança da categoria gestão dos cuidados, a maioria dos Enfermeiros Gestores respondem "sempre" para quase todas as questões, exceto para as dimensões: atua como formador na equipa multi e infra disciplinar, apenas $(28,6 \%)$ referem "sempre"; promove e avalia a satisfação profissional dos enfermeiros e de outros colaboradores, (25,4\%) respondem "sempre". Analogicamente, os autores elencaram a necessidade dos Enfermeiros Gestores fazerem formação na área da gestão como uma premissa importante, objetivando alterar o seu estilo de liderança, promovendo a autorreflexão dos Enfermeiros Gestores e consequentemente diligenciando práticas mais adequadas aos seus contextos de trabalho, Camelo, H. et al. (2017); Chipeta, E. et al. (2016); Lelli, L. et al. (2012) e Munyewende, P. et al. (2016). 
Na área de componente Intervenção Politica e Assessoria responderam que adaptam "sempre" os recursos materiais às necessidades, tendo em conta a relação custo-benefício $(55,6 \%)$. Finalizando, na componente Desenvolvimento Profissional, foram abordadas quatro dimensões, tendo-se verificado que cerca de mais de metade das respostas foi "sempre", quando se posicionam face à estimulação dos enfermeiros à autoformação $(65,1 \%)$.

Comparativamente, vários estudos catalogaram a importância da capacidade de liderança dos Enfermeiros Gestores como competência capital nas funções de gestão. No entanto, privilegiam ainda fatores como: a negociação, a análise e soluções de problemas; o comprometimento e orientação para os resultados; a comunicação e partilha de conhecimentos; o trabalho em equipa e a tomada de decisão Lelli, L. et al (2012); Fradique, M. e Mendes, L. (2013); Chipeta, E. et al. (2016); Munyewende, P. et al. (2016); Camelo, H. et al. (2017).

Nesta discussão consideramos importante o facto de outros autores referenciarem nas competências de gestão dos enfermeiros o estilo de liderança como um fator decisivo para a motivação da equipa. Corroboramos com os diversos estudos, quando referem que a melhoria da satisfação profissional dos colaboradores é crucial para a alta qualidade dos cuidados e são a garantia da eficiência na prestação de cuidados de saúde, Camelo et al. (2016), Vesterinen et al. (2012) e Chipeta et al. (2016). O Enfermeiro Gestor é considerado o profissional que detém competências para se equiparar ao verdadeiro "motor" oferecendo energia e motivação para a mudança nas organizações de saúde.

Conclusão: Constatamos que a necessidade de formação está patente nas diferentes dimensões das competências: Prática Profissional Ética e Legal, Gestão Cuidados, Gestão Recursos Humanos, Intervenção Politica e Assessoria e Desenvolvimento Profissional.

Comprovamos que os enfermeiros gestores a sua maioria não possuem formação específica na área de gestão que alicerce com conhecimentos o cargo de gestão que ocupa. A concretização desta investigação revelou uma indiscutível necessidade de implementar práticas formativas nos contextos das chefias em enfermagem, com a finalidade de aprimorar as competências acrescidas avançadas dos enfermeiros gestores e líderes.

Considera-se como fragilidade do estudo a utilização de um questionário, pois impediu de ter uma resposta da noção do nível de compreensão das questões, considerando-se que não ocorreu contacto verbal com as pessoas envolvidas, não permitindo assim aprofundar respostas que suscitem maior esclarecimento. 
Este estudo contribuiu para a tomada de consciência de que o Enfermeiro Gestor nesta região insular tem necessidades de formação em contexto de trabalho ao nível das competências acrescidas avançadas. Pretendemos que os pontos mais relevantes deste estudo sirvam de subsídios para a realização de novos estudos neste mesmo âmbito.

\section{Referências Bibliográficas}

[1] Camelo, S., Silva, V., Soares, M., Resck, Z., Chaves, 1., Santos, F. (2016). Práticas de liderança em enfermagem hospitalar: uma self de enfermeiros gestores. Rev Esc Enferm USP. Brasil, 1-8. [consultado a 04/05/2019]. Disponível em: http://www.scielo.br/pdf/reeusp/v51/pt 1980-220X-reeusp-51-e03206.pdf

[2] Carvalho, L., Bernardo, M., Sousa, I.; Negas, M. (2015). Gestão das organizações: uma abordagem integrada e prospetiva. 2a ed. Lisboa: Edições Silabo, Lda, 2015.

[3] Ceitil, M. (2016). Gestão e Desenvolvimento de Competências. 2a ed, Lisboa: Edições Silabo, Lda, 2016.

[4] Chipeta, E., Bradley, S., Manda, W., McAuliffe, E. (2016). Working relationships between obstetric care staff and their managers: a critical incident analysis. BMC Health Services Research, Malawi. 1-9. [Consultado a 04/04/2019]. Disponível em: https://bmchealthservres.biomedcentral.com/track/pdf/10.1186/s12913-016-1694-x

[5] Costa, T. (2018). Gestão Contemporânea: Princípios, Tendências e Desafios. 2a ed. Lisboa. Edições Silabo, 2018.

[6] Decreto-Lei no 71/2019. D. R. I Série, Nª101 (2019/05/27), 2626-2642.

[7] Decreto-Lei no 161/96. D.R. I Série-A. Nº 205 (1996-09-04), 2959-2962. (Regulamento do Exercício Profissional do Enfermeiro)

[8] Decreto Legislativo Regional n. ${ }^{\circ}$ 28/99/A, (1999/07/31), 1942-1952.

[9] Fradique, M. \& Mendes, L. (2013). Efeitos da liderança na melhoria da qualidade dos cuidados de enfermagem. Revista de Enfermagem de Referência, III (10), 45-53. [consultado a 04/02/2019]. Disponível em: http://www.scielo.mec.pt/pdf/ref/vserIIIn10/serIIIn10a06.pdf

[10] Lelli, L., Bernardino, E., Peres, A., Fabriz, 1., (2012). Estratégias gerenciais para o desenvolvimento de competências em enfermagem em hospital de ensino. Cogitare Enfermagem. 2, Abril - Junho de 2012, Vol. 17, 262 - 269. [Consultado a 04/04/2019]. Disponível em: https://revistas.ufpr.br/cogitare/article/view/24932/18480 
[11] Moura, A., Bernardes, A. \& Balsanelli, A. (2017) Liderança e satisfação no trabalho em enfermagem: revisão integrativa. Acta Paulina Enfermagem, 30 (4), 442-450. [Consultado a 04/04/2019]. Disponível em: http://www.scielo.br/pdf/ape/v30n4/01032100-ape-30-04-0442.pdf

[12] Munyewende, P., Levin, J. \& Rispel, L. (2016). An evaluation of the competencies of primary health careclinic nursing managers in two South African provinces. Global Health Action. Africa do Sul, 9 dez. 2016, 1-11. [consultado a 04/02/2019]. Disponível em: https://www.ncbi.nlm.nih.gov/pmc/articles/PMC5149665/pdf/GHA-9-32486.pdf

[13] Ordem dos Enfermeiros. (2015). REPE e Estatuto. Lisboa: Ordem dos enfermeiros.

[14] Ordem dos Enfermeiros. (2018). Relatório de Contas: Membros ativos. Lisboa: Ordem dos Enfermeiros

[15] Ordem Dos Enfermeiros. (2015). Regulamento no 101/2015 - Regulamento do Perfil de Competências do Enfermeiro Gestor. Diário da República. 10 de março de 2015, Vol. 2o Série no 48, 5948-5952.

[16] Regulamento nº.76/2018. D.R. II Série. No21 (2018-01-30), 3478-3487.

[17] Rocha, MCJ; Sousa, P. \& Martins, M. A opinião dos enfermeiros diretores sobre a intervenção do enfermeiro chefe. Investigação em Enfermagem. 18, 2016, Vol. 2, pp. 89105. http://dx.doi.org/10.11144/Javeriana.ie18- 2.aoed

[18] Vesterinen, S., Suhonen, M., Isola, A., Paasivaara, L. (2012). Nurse Managers' Leadership Styles in Finland. Nursing Research and Practice. Finlândia, Volume 2012, Article ID 605379, 1-8. [consultado a 04/04/2019]. Disponível em: https://www.hindawi.com/journals/nrp/2012/605379/abs/ 